\section{Violência Obstétrica e Bioética à luz da Declaração Universal sobre Bioética e Direitos Humanos}

\section{Albuquerque, Raylla}

Programa de Pós-graduação em Bioética - Universidade de Brasília (UnB). E-mail rayllaalbuquerques@gmail.com

\section{Monsores, Natan}

Observatório de Doenças Raras - Programa de Pósgraduação em Bioética - Universidade de Brasília (UnB)

PALAVRaS CHAVE: Bioética, Violência, Direitos Humanos, Humanização, Parto

INTRODUÇÃO. Pesquisas em todo o mundo demonstram que mulheres têm sido vítimas de negligência, violência física, violência verbal e violência sexual dentro das instituições de saúde - em especial ao dar à luz. Considerando o papel dos profissionais no que se refere a esse cenário, o presente estudo teve como objetivo conhecer a percepção dos estudantes da área da saúde sobre a violência obstétrica e sua relação com a Bioética, conforme princípios previstos na Declaração Universal sobre Bioética e Direitos Humanos (DUBDH). MÉTODOS. Realizou-se, mediante aprovação pelo CEP, pesquisa exploratória de abordagem mista com 102 estudantes em todos os níveis de formação. O instrumento foi questionário estruturado, disponibilizado por meio eletrônico, composto por questões abertas e fechadas. A análise de dados incluiu técnicas de estatística descritiva para os dados quantitativos e análise de conteúdo para os qualitativos, à luz da Declaração Universal sobre Bioética e Direitos Humanos. RESULTADOS. A amostra foi composta majoritariamente por participantes do sexo feminino, com até 25 anos de idade, residentes no Distrito Federal e que não possuem filhos - mais da metade informou ser estudante de graduação, nas áreas de enfermagem e medicina. A violação aos princípios do "Respeito à Vulnerabilidade Humana e pela Integridade Individual" e "Dignidade Humana e Direitos Humanos" foram indicados por aproximadamente $80 \%$ dos participantes como relacionados com a ocorrência de Violência Obstétrica. Para os participantes, o desrespeito a esses princípios está diretamente relacionado ao uso de procedimentos inadequados, ou que não deveriam ser realizados, bem como às violências físicas, verbais e sexuais - além do desrespeito à lei do acompanhante. A vulnerabilidade da mulher no processo de parto está relacionada, principalmente, ao desconhecimento sobre seus direitos, seu corpo e sobre os tipos de assistência. A adoção de condutas desnecessárias e sem respaldo científico configuram violações à integridade corporal da mulher, à sua dignidade e aos direitos humanos. Em relação à bioética, a pesquisa demonstrou que, embora quase a totalidade dos participantes tenha referido alguma familiaridade com o tema, a maioria demonstrou não conhecer ou conhecer parcialmente os princípios da DUBDH - o que denota uma lacuna na formação dos profissionais de saúde. CONCLUSÕES. Embora a ocorrência de violência obstétrica seja multifatorial, as principais práticas caracterizadas pelos participantes como violência referem-se a condutas não éticas, na avaliação dos mesmos. Os achados da pesquisa evidenciaram a importância da utilização de referenciais bioéticos para o enfrentamento da violência obstétrica, além de maior fiscalização e controle dos profissionais envolvidos.

\section{REFERÊNCIAS}

[1] d'Oliveira AFPL, Diniz SG, Schraiber LB. Violence against women in health-care institutions: an emerging problem. Lancet. 2002; 359(11):1681-5.

[2] World Health Organization. The prevention and elimination of disrespect and abuse during facility-based childbirth. [Internet] WHO; 2014.

[3] Organização das Nações Unidas para a Educação, a Ciência e a Cultura. Declaração Universal sobre Bioética e Direitos Humanos. [Internet]. Paris: Unesco; 2005.

[4] Diniz SG, Salgado HO, Andrezzo, HFA, Carvalho PGC, Carvalho, PCA, Aguiar CA, et al. Violência obstétrica como questão para a saúde pública no Brasil: origens, definições, tipologia, impactos sobre a saúde materna, e propostas para sua prevenção. Rev Bras Crescimento Desenvolv Hum. 2015; 25(3):377-84

[5] Cunha T, Garrafa V. Vulnerabilty: A Key Principle for Global Ethics? Cambridge University. 2016; 25(2):197-208. 